\title{
Walking in Natural Environments as Geriatrician's Recommendation for Fall Prevention: Preliminary Outcomes from the "Passiata Day" Model
}

\author{
Giuseppe Battaglia ${ }^{1,2}\left(\mathbb{D}\right.$, Valerio Giustino ${ }^{1,3}$, Giuseppe Messina ${ }^{1,4, *}$, Mariangela Faraone 5 , \\ Jessica Brusa ${ }^{1}$, Anna Bordonali ${ }^{5}$, Mario Barbagallo ${ }^{5}$ (D) Antonio Palma ${ }^{1,2,6}$ and \\ Ligia-Juliana Dominguez ${ }^{5}$ (D) \\ 1 Department of Psychology, Educational Science and Human Movement, University of Palermo, \\ Via Giovanni Pascoli, 6, 90144 Palermo, Italy; giuseppe.battaglia@unipa.it (G.B.); \\ valerio.giustino@unipa.it (V.G.); brusajessica@gmail.com (J.B.); antonio.palma@unipa.it (A.P.) \\ 2 Sport and Exercise Sciences Research Unit, University of Palermo, Via Giovanni Pascoli, 6, \\ 90144 Palermo, Italy \\ 3 PhD Program in Health Promotion and Cognitive Sciences, University of Palermo, Via Giovanni Pascoli, 6, \\ 90144 Palermo, Italy \\ 4 Posturalab Italia Research Institute, Via Santicelli 4, 90131 Palermo, Italy \\ 5 Geriatric Unit, Department of Internal Medicine and Geriatrics, University of Palermo, Via del Vespro, 129, \\ 90127 Palermo, Italy; mariangela.faraone@libero.it (M.F.); a.bordonali@gmail.com (A.B.); \\ mario.barbagallo@unipa.it (M.B.); ligia.dominguez@unipa.it (L.-J.D.) \\ 6 Regional Sports School of CONI Sicilia, Sicily, Italy, Via Emanuele Notarbartolo, 1/G, 90141 Palermo, Italy \\ * Correspondence: giuseppe.messina17@unipa.it
}

Received: 7 February 2020; Accepted: 23 March 2020; Published: 29 March 2020

check for updates

Abstract: Background: The Geriatric Unit of the University of Palermo developed the "Passiata Day" model, a green exercise intervention consisting of a one-hour walk, once/week, in a city park. The purpose of this study was to assess body balance in older people who walked regularly compared to sedentary people. Methods: 106 older people (75 women and 31 men; mean age: $72.3 \pm 8.2$ years) without fall history were invited to participate voluntarily in this natural environment walking program. After six months, both the participants who had taken part regularly in the walk (i.e., the physical activity group (PAG; $\mathrm{n}=72 ; 54$ women and 18 men; mean age: $70.7 \pm 7.2$ years)), and who had not accepted to be included in the outdoor walking program (i.e., the sedentary group (SG; $\mathrm{n}=34 ; 21$ women and 13 men; mean age: $75.5 \pm 9.4$ years)), performed a stabilometric test with open eyes (OE) and with closed eyes (CE). Results: Our preliminary results showed significant differences between groups on the ellipse sway area both in the OE $(p<0.05)$ and in CE condition $(p<0.01)$. Moreover, we found a significant difference on sway along the frontal plane both in the OE $(p<0.05)$ and in the CE condition $(p<0.01)$, and on sway along the sagittal plane for the test with CE $(p<0.01)$. Conclusion: Based on our preliminary findings, we suggest that walking regularly in an outdoor setting could lead to a greater body balance in older people and could be recommended by geriatricians for preventing the risk of falls. The next step will be to investigate the effect of an experimental outdoor walking program structured in terms of intensity, frequency and volume.

Keywords: green exercise; sustainable exercise; outdoor exercise; walking program; body balance; postural control; older people; elderly; falls prevention; risk of falls

\section{Introduction}

Falls, defined as the events in which people inadvertently lose vertical status coming down to rest on the ground, represent the second highest cause of death in the world among incidents and are 
an important problem for older people [1,2]. According to the World Health Organization, each year, the percentage of people aged 65 to 69 years who fall is between 28 and 35, and from 32 to $42 \%$ among older people over 70 years of age [1]. As reported by a former study by Lord et al., approximately one-third of people aged 65 years and over experience at least one episode of falling each year [3].

The scientific literature reported that fall-related risk factors in older people can be classified into intrinsic and extrinsic factors. The latter regard the environmental conditions as lighting, the floor and the type of footwear [4]. Concerning the intrinsic factors, they include age-related hearing/visual loss, vestibular failure and musculoskeletal impairments [5]. The functional decay of organs for sight and hearing as well as of the musculoskeletal system leads to a worsening of postural control and an alteration of body balance, increasing the risk of falling in old age [6]. As body balance, namely the ability to control the displacement of the body's center of mass (CoM), depends on the interaction of information from these organs integrated by the central nervous system (CNS), the physiological decline as well as the pathological conditions of one or more of these systems produces a substantial alteration of static body balance, dynamic postural control and gait patterns, causing a high risk of falls, particularly in older individuals [7-9].

Moreover, it is well-known that falls are a common and potentially relevant health risk in older people causing a high rate of morbidity and mortality $[10,11]$. The epidemiology of these accidental episodes in older people and their complications are various and can require medical treatment or, in the most serious cases, hospitalization [10]. In particular, among older adults, more than $50 \%$ of these episodes require hospitalizations, implementing fall-related costs for health public systems [12]. For these reasons, fall prevention interventions are a priority for public health systems in order to reduce fall-related high costs, sensitize people on health programs benefits, and improve life quality $[13,14]$.

It is widely recognized that, among the interventions in older people, physical activity programs have shown beneficial effects on mental health as well as physical features, including an increase on body balance ability, a fundamental characteristic in order to prevent falls [15-17]. Studies aiming to examine and compare the effects of exercise on falls prevention should consider the characteristics of physical activity programs in terms of intensity, frequency and volume, as well as the training setting (e.g., supervised vs. unsupervised training, group exercise intervention vs. individual training, home exercise program vs. structured physical activity program vs. leisure-time physical activity, indoor vs. outdoor setting) [12,18-23]. Among the key topics addressed in a recent review, focused on the fall prevention in elderly, was included the role of outdoor training providing an interesting contribution on fall-reducing effects in elderly of this latter training setting [22]. Indeed, although a number of different convincing evidence emphasize the potential benefits of practicing physical exercise in natural environments in a wide range of physical and psychological hallmark [24-26], the contribution of this seminal review is considerable since Karlsson et al. reported that elderly who walk outdoors with technical shoes encounter a reduction of fall risks [22]. Regarding the types of exercise, although the literature is in agreement that balance exercises would seem to be the most effective, some authors have investigated the role of endurance, resistance training or walking programs on the reduction in the fall risk and on fall rates in healthy older adults as well as in those at risk of falling reporting conflicting results [12,27-29]. As concern walking plans, it is well known that this type of physical activity is able to induce benefits of a multitude of physical fitness parameters, including posture, in young people as well as in older adults [30]. However, Sherrington et al. showed that walking significantly increased falls in elderly at risk of falling and with different history of falling [12], while Okubo et al. reported a significant reduction of fall risk with brisk walking with respect to balance and strength training among healthy older people living in the community [31].

Walking is a healthy activity characterized by a simple structure and easy accessibility with no need of sports background, representing the most natural form of exercise [32]. In agreement with several studies in the literature, which found neuromuscular modifications depending on long-term regular walking training in active participants compared with sedentary ones [33,34], we hypothesize that a light physical activity, like an outdoor walking experience, could positively affect body balance 
in older people in a similar way. Therefore, the purpose of this study was to evaluate the effects of a no-structured six-month regular walking in a natural environment on body balance and postural control strategies in a sample of older adults without fall history.

\section{Materials and Methods}

\subsection{Study Design and Participants}

An unrandomized, comparative, retrospective hospital-based case study was adopted for the research. The recruitment, conducted by the geriatrician of the Department of Internal Medicine and Geriatrics of the University Hospital of Palermo (Italy), took place at the geriatric ambulatory clinic of the same institution, during the year 2017 as part of a fall prevention and health promotion program. The participants were invited to participate voluntarily in the "Passiata Day" model, an initiative of this department that provided a one-hour walk once a week in a park of Palermo city, during which subjects were asked to walk in a group maintaining a leisurely pace. This outdoor walking plan was guided by a graduate in physical education and a geriatrician. The patients were deemed suitable for the study if they met the following inclusion criteria: sedentary lifestyle and physically inactive [35]; no history of falling; absence of musculoskeletal injury, cognitive disables, and/or hearing impairment. In order to establish the compatibility with the inclusion criteria, information collection was recorded using a questionnaire to which participants were asked to respond by interview. Based on the aforementioned inclusion criteria, 106 older people with an age range from 60 to 90 years (75 women and 31 men; mean age: $72.3 \pm 8.2$ years; height: $159.4 \pm 12.6 \mathrm{~cm}$; weight: $70.5 \pm 16.7 \mathrm{~kg}$ ) were eligible for the study, but only 72 participants (Physical activity group (PAG); 54 women and 18 men; mean age: $70.7 \pm 7.2$ years; height: $160.4 \pm 7.4 \mathrm{~cm}$; weight: $70.4 \pm 13.9 \mathrm{~kg}$ ) accepted following the outdoor walking plan. The subjects have not provided indications of changing their usual physical activity. In order to participate in the study all participants provided a signed informed consent form. The study was developed in accordance with the Declaration of Helsinki regarding the criteria for the participation of persons in research and approved by the Ethical Board of the University of Palermo.

\subsection{Data Collection}

Six-months after the beginning of the outdoor walking program, a group of researchers of the Sport and Exercise Sciences Research Unit of the same university evaluated body balance of the participants who had accepted the geriatrician recommendation to walk regularly in the "Passiata Day" model for this period (PAG) and of the participants who had not taken part in this outdoor walking plan (Sedentary group (SG); 21 women and 13 men; mean age: $75.5 \pm 9.4$ years; height: $157.3 \pm 19.6 \mathrm{~cm}$; weight: $70.9 \pm 21.6 \mathrm{~kg}$ ).

\subsection{Anthropometric Measurements}

The anthropometric measurements were recorded with the participants wearing only undergarments. Body weight was assessed using a Seca electronic scale (maximum weight recordable: $300 \mathrm{~kg}$; resolution: $100 \mathrm{~g}$; Seca, Hamburg, Germany). Height was determined using a standard stadiometer (maximum height recordable: $220 \mathrm{~cm}$; resolution: $1 \mathrm{~mm}$ ). Body mass index (BMI) was calculated indirectly as body weight divided by height squared $\left(\mathrm{kg} / \mathrm{m}^{2}\right)$.

\subsection{Stabilometric Evaluation}

It is widely recognized in the scientific literature that the stabilometric test provides valid outcomes that allows prediction of the risk of falling in elderly with and without fall history [36]. For this reason, in order to assess body balance, all participants of both groups performed a stabilometric evaluation and repeated the test under two different conditions: with open eyes (OE) and with closed eyes $(\mathrm{CE})$ using the freeMed®platform and the freeStep $\Re$ software v.1.6.007 (Sensor Medica $®$; Guidonia Montecelio, Roma, Italia) and sampling real time postural sway at $50 \mathrm{~Hz}$. In accordance with the 
Romberg test, participants were required to stay barefoot in an orthostatic position with the head in neutral position for 51.2 seconds with feet placed side-by-side forming an angle of $30^{\circ}$ and both heels $4 \mathrm{~cm}$ apart [37]. We considered the following parameters of the center of pressure (CoP) for statistical analysis: sway path length (SPL) of the CoP; ellipse sway area (ESA) of the CoP; CoP coordinates along the frontal $(\Delta \mathrm{X} ; \mathrm{X}$-mean) and sagittal $(\Delta \mathrm{Y} ; \mathrm{Y}$-mean) planes (Figure 1$)$.

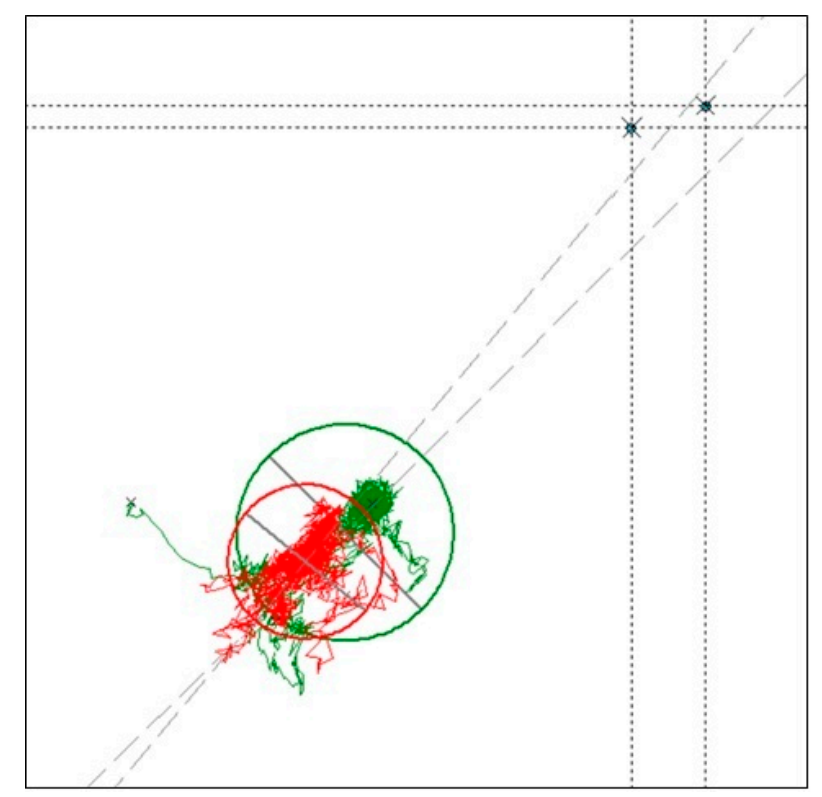

Figure 1. Statokinesigram of the stabilometric test. In green, test with open eyes (OE); in red, test with closed eyes (CE).

\subsection{Statistical Analysis}

Statistical analysis was performed using Statistica software v.12 (StatSoft $®$, TIBCOßSoftware Inc, Palo Alto, CA, USA). All data are presented as means \pm standard deviations with the alpha level set at $p<0.05$ to be considered statistically significant. Normality of the data distribution was tested using the Kolmogorov-Smirnov test. Differences between groups were computed via unpaired Student's $t$-test and the homogeneity of variances was verified by the Levene's test $(F)$. Furthermore, the Cohen's $d$ was calculated using G*Power software v.3.1.9.2 (Heinrich Heine University, Düsseldorf, Germany) and we interpreted the magnitude of the effect size considering the criterions reported by Cohen (small effect: $\geq 0.2$, medium effect: $\geq 0.5$, large effect: $\geq 0.8$ ] [38].

\section{Preliminary Results}

Data investigations revealed a normal distribution of variance. Comparing the two groups (i.e., PAG vs. SG), our results showed significant differences on the ESA stabilometric parameter in both the $\mathrm{OE}$ and $\mathrm{CE}$ conditions. In particular, we found a significant lower mean value of ESA in the PAG respect to the SG for the stabilometric test with OE condition $(p=0.04)$, as well as for the CE condition $(p=0.008)$, as reported in Tables 1 and 2. Moreover, we observed a significant difference between the groups on $\Delta \mathrm{X}$ in both tests (respectively $p=0.04$ for the $\mathrm{OE}$ condition and $p=0.001$ for the $\mathrm{CE}$ condition) and on $\Delta Y$ for the evaluation with CE $(p=0.009)$. Furthermore, although not statistically significant, the PAG showed lesser values compared to the SG for all the other parameters $(p>0.05)$ both in the trial with $\mathrm{CE}$ and with $\mathrm{OE}$. 
Table 1. Values of CoP coordinates on stabilometric test with open eyes (OE) in both groups (SG vs. PAG).

\begin{tabular}{ccccccccc}
\hline & SG & PAG & $p$ Value & $\mid$ MD $\mid$ & $t$ Value & $\boldsymbol{F}_{(\mathbf{1}, \mathbf{1 0 4})}$ & $p$ Levene & Cohen's $\boldsymbol{d}$ \\
\hline ESA $\left(\mathbf{m m}^{\mathbf{2}}\right)$ & $166.19 \pm 191.04$ & $109.9 \pm 85.71$ & 0.04 & 56.29 & -2.1 & 11.26 & 0.001 & 0.38 \\
SPL $(\mathbf{m m})$ & $494.94 \pm 122.13$ & $484.6 \pm 142.87$ & n.s. & 10.35 & -0.36 & 0.61 & n.s. & 0.08 \\
$\mathbf{\Delta X}(\mathbf{m m})$ & $14.32 \pm 8.5$ & $11.52 \pm 5.12$ & 0.04 & 2.8 & -2.11 & 9.95 & 0.002 & 0.4 \\
$\mathbf{\Delta Y}(\mathbf{m m})$ & $15.28 \pm 8.1$ & $13.46 \pm 6.83$ & n.s. & 1.82 & -1.2 & 0.82 & n.s. & 0.24 \\
X-mean (mm) & $-4.28 \pm 9.35$ & $-2.77 \pm 10.06$ & n.s. & 1.51 & 0.74 & 0.67 & n.s. & 0.16 \\
Y-mean (mm) & $-11.2 \pm 8.37$ & $-11.5 \pm 9.45$ & n.s. & 0.3 & -0.16 & 1.26 & n.s. & 0.03 \\
\hline Legend: CoP, Center of Pressure; SG, Sedentary Group; PAG, Physical Activity Group; MD, Mean Absolute \\
Difference; ESA, Ellipse Sway Area; SPL, Sway Path Length; $\Delta$ X and X-mean, Right and Left Sway; $\Delta$ Y and Y-mean, \\
Forward and Backward Sway; n.s., non-significant.
\end{tabular}

Table 2. Values of CoP coordinates on stabilometric test with closed eyes (CE) in both groups (SG vs. PAG).

\begin{tabular}{|c|c|c|c|c|c|c|c|c|}
\hline & SG & PAG & $p$ Value & $|\mathrm{MD}|$ & $t$ Value & $F_{(1,104)}$ & $p$ Levene & Cohen's $d$ \\
\hline $\operatorname{ESA}\left(\mathrm{mm}^{2}\right)$ & $221.08 \pm 360.48$ & $92.04 \pm 125.44$ & 0.008 & 129.03 & -2.72 & 16.26 & 0.0001 & 0.48 \\
\hline SPL (mm) & $575.61 \pm 167.82$ & $537.9 \pm 158.86$ & n.s. & 37.7 & -1.12 & 0.01 & n.s. & 0.23 \\
\hline$\Delta \mathrm{X}(\mathrm{mm})$ & $15.28 \pm 10.01$ & $9.97 \pm 6.19$ & 0.001 & 5.31 & -3.35 & 12.59 & 0.0006 & 0.64 \\
\hline$\Delta \mathrm{Y}(\mathrm{mm})$ & $18.35 \pm 14.06$ & $12.71 \pm 7.7$ & 0.009 & 5.64 & -2.67 & 12.91 & 0.0005 & 0.5 \\
\hline X-mean (mm) & $-2.82 \pm 7.77$ & $-1.37 \pm 10.51$ & n.s. & 1.45 & 0.72 & 2.3 & n.s. & 0.16 \\
\hline Y-mean (mm) & $-13.43 \pm 9.18$ & $-10.13 \pm 7.99$ & n.s. & 3.3 & 1.89 & 0.89 & n.s. & 0.38 \\
\hline
\end{tabular}

Legend. CoP, Center of Pressure; SG, Sedentary Group; PAG, Physical Activity Group; MD, Mean Absolute Difference; ESA, Ellipse Sway Area; SPL, Sway Path Length; $\Delta \mathrm{X}$ and X-mean, Right and Left Sway; $\Delta \mathrm{Y}$ and $\mathrm{Y}$-mean, Forward and Backward Sway; n.s., non-significant.

\section{Discussion}

\subsection{Walking to Prevent/Reduce Falls in Older People}

Evidence of the effectiveness of exercise interventions for the prevention of falls in older adults is well known in the scientific literature $[39,40]$. Among the physical activity interventions, walking exercise, individualized in intensity, duration and frequency, can be practiced safely by everyone except for disabled people [30]. For these reasons, keeping in mind that the lack of the initial assessment did not allow evaluation of the within-group effect of the walking plan, the aim of this study was to examine body balance, measured by stabilometric test, in a group of older adults who had walked regularly for six months in a natural environment compared to a sedentary group. Although significant differences between groups were found on $\mathrm{CoP}$ coordinates along the frontal plane both with $\mathrm{OE}$ and in CE ( $p<0.05$ and $p<0.01$ respectively), and on CoP coordinates along the sagittal planes for the evaluation with $C E(p<0.01)$, the main finding of the present study was that PAG showed a significant difference on the ellipse sway area in the test with $\mathrm{OE}(p<0.05)$ as well as for the CE condition test $(p<0.01)$ compared to the sedentary group. Comparisons between groups showed lower values in the PAG with respect to the SG in all other parameters of the CoP in the CE condition test, as well as in the assessment with $\mathrm{OE}$ that did not reach statistical significance.

Based on our preliminary findings, we suggest that, in a group of healthy older people a light physical activity, even if not structured (in terms of intensity, frequency and volume), like an outdoor walking plan, could lead to a greater body balance. Lee et al. reported the positive influence of walking on chronic diseases (e.g., cardiovascular disease, hypertension, diabetes, osteoporosis, obesity), as well as on disorders as anxiety or depression, recommending this physical activity as an important therapeutic strategy for patients [32]. In addition to these known benefits, a review by Morris et al. reported that walking programs may induce improvements in posture [30]. Whereas many authors agree that balance training seems to be the most suitable for preventing the risk of falls, conflicting results were reported in the scientific literature concerning the effectiveness of walking [41-43]. It is fundamental to consider if older people enrolled in the studies are healthy, as in our study, or at risk of falling. Indeed, though walking represents the most simple structure of physical activity and healthy people should be encouraged to walk as much as possible, we suggest, in agreement with Gillespie et 
al., that due to the possibility of stumbling or slipping inherent in this activity, walking should not be recommended in the elderly at risk of falling [28]. Other authors had previously investigated the usefulness of walking plans on fall reduction, either as a unique exercise training or combined in a protocol of different types of exercise [31,44]. Okubo et al. reported that in older adults with no risk of falling walking improved body balance and as a result was useful in order to prevent falls [31].

\subsection{Walking in Natural Environments}

In an attempt to explain the greater body balance found in the PAG in our preliminary outcomes, we hypothesize that walking in the park, due to the irregular ground, stimulated the foot more than a solid surface, which could have increased the ability of the walkers to respond to an unstable surface similarly as a proprioceptive training [45]. Moreover, we assume that walking in a natural environment without constraints related to speed and at a favorable gait is advantageous for older people. Our preliminary results are further supported by a study of Row Lazzarini et al., in which the authors reported that treadmill walking is problematical for older people [46]. Furthermore, as evidenced in the literature, green exercise, such as walking or running, seems to be associated with positive effects on many physical and cognitive features [47], and, in keeping with our preliminary results, Karlsson et al. have found that walking outdoor with anti-slip shoe devices is effective in reducing the risk of fall in the elderly [22]. Nevertheless, it is noteworthy that recently several researches confirmed the importance to advise against walking as an activity for people at risk of falls or with a history of falling, but they underline the fundamental role of physical activity in order to reduce fall rates in old age $[48,49]$.

\subsection{Strengths and Limitations of the Study}

The present study has clarified that healthy older people who walk regularly show greater body balance than age-matched sedentary people. The main strength of our study is the great advantage of this exercise intervention, that is the easiness in terms of accessibility. Moreover, our main content is promoting the practice of a simple and no-structure light physical activity in an outdoor environment as a possible approach that could lead to greater body balance in older people for preventing the risk of falls.

However, the principal limitation of the current study is that it does not include postural assessment prior to the walking plan, which precludes assessing the within-group effect of this exercise intervention.

From a practical point of view, this investigation promotes the potential effect of walking on preventing falls in elderly people without history of falls. As such, our study did not provide information on the role of walking in elderly people with a history of falls, and for this reason our results should be interpreted considering this population context and should not be generalized.

In summary, this research has emphasized that walking could lead to a greater static body balance in elderly people without history of falls, and for this reason further studies are needed to examine, firstly, the effect of walking on elderly people with a history of falls and, subsequently, on dynamic body balance and walking pattern for both elderly populations (i.e., non-fallers and fallers).

\subsection{Conclusions}

Based on these preliminary outcomes, we suggest that walking regularly in an outdoor setting, as done for the "Passiata Day" model, could be recommended from geriatricians in order to help prevent the risk of falls in older people. Our preliminary findings need further research in order to confirm the hypothesis that a leisure-time physical activity such as walking regularly in a naturals environment could be an intervention that induces a greater body balance and consequently prevent the risk of falls in healthy older people (e.g., comparing a walking plan in different environments like outdoor vs. indoor vs. treadmill). Moreover, given the preliminary findings of our study on the benefits of a no-structured outdoor walking plan for the elderly, the next step will be to investigate the effect of an experimental outdoor walking program structured in terms of intensity, frequency and volume 
based on previous researches and guidelines [50-53]. It is recommended that these outdoor walking programs are carried out in a group, as recent research has showed that physical activity as part of a group is associated with higher enjoyment levels and higher levels of activity [54].

Author Contributions: Conceptualization, L.-J.D., A.P., M.B.; Methodology and Study Design, G.B.; Data Collection, M.F., J.B., A.B.; Data Analysis, V.G.; Data Interpretation, G.B. and G.M.; Writing - Original Draft Preparation, V.G.; Writing - Review \& Editing, G.B.; Visualization, L.-J.D. and G.M.; Project Administration, A.P. and M.B. All authors have read and agreed to the published version of the manuscript.

Funding: The authors declare no funding received.

Conflicts of Interest: The authors declare no conflict of interest.

\section{References}

1. World Health Organization. Ageing and Life Course Unit. In WHO Global Report on Falls Prevention in Older Age; World Health Organization: Geneva, Switzerland, 2008.

2. Zlatar, T.; Lago, E.M.G.; Soares, W.D.A.; Baptista, J.D.S.; Barkokébas Junior, B. Falls from height: Analysis of 114 cases. Production 2019, 29. [CrossRef]

3. Lord, S.R.; Ward, J.A.; Williams, P.; Anstey, K.J. An epidemiological study of falls in older community-dwelling women: The Randwick falls and fractures study. Aust. J. Public Health 1993, 17, 240-245. [CrossRef]

4. Spoelstra, S.L.; Given, B.A.; Given, C.W. Fall prevention in hospitals: An integrative review. Clin. Nurs. Res. 2012, 21, 92-112. [CrossRef]

5. Callis, N. Falls prevention: Identification of predictive fall risk factors. Appl. Nurs. Res. 2016, $29,53-58$. [CrossRef]

6. Lajoie, Y.; Gallagher, S.P. Predicting falls within the elderly community: Comparison of postural sway, reaction time, the Berg balance scale and the Activities-specific Balance Confidence (ABC) scale for comparing fallers and non-fallers. Arch. Gerontol. Geriatr. 2004, 38, 11-26. [CrossRef]

7. Toledo, D.R.; Barela, J.A. Age-related differences in postural control: Effects of the complexity of visual manipulation and sensorimotor contribution to postural performance. Exp. Brain Res. 2014, 232, 493-502. [CrossRef]

8. Ishiyama, G. Imbalance and vertigo: The aging human vestibular periphery. Semin. Neurol. 2009, 29, 491-499. [CrossRef]

9. Messina, G. The Tongue, Mandible, Hyoid System. Eur. J. Transl. Myol. 2017, 27, 74-76. [CrossRef]

10. Rubenstein, L.Z. Falls in older people: Epidemiology, risk factors and strategies for prevention. Age Ageing 2006, 35 (Suppl. 2), ii37-ii41. [CrossRef]

11. Cuevas-Trisan, R. Balance Problems and Fall Risks in the Elderly. Phys. Med. Rehabil. Clin. 2017, 28, 727-737. [CrossRef]

12. Sherrington, C.; Whitney, J.C.; Lord, S.R.; Herbert, R.D.; Cumming, R.G.; Close, J.C. Effective exercise for the prevention of falls: A systematic review and meta-analysis. J. Am. Geriatr. Soc. 2008, 56, 2234-2243. [CrossRef] [PubMed]

13. Atienza, A.A.; King, A.C. Community-based health intervention trials: An overview of methodological issues. Epidemiol. Rev. 2002, 24, 72-79. [CrossRef] [PubMed]

14. Florence, C.S.; Bergen, G.; Atherly, A.; Burns, E.; Stevens, J.; Drake, C. Medical Costs of Fatal and Nonfatal Falls in Older Adults. J. Am. Geriatr. Soc. 2018, 66, 693-698. [CrossRef]

15. Battaglia, G.; Bellafiore, M.; Alesi, M.; Paoli, A.; Bianco, A.; Palma, A. Effects of an adapted physical activity program on psychophysical health in elderly women. Clin. Interv. Aging 2016, 11, 1009-1015. [CrossRef]

16. Patti, A.; Bianco, A.; Karsten, B.; Montalto, M.A.; Battaglia, G.; Bellafiore, M.; Cassata, D.; Scoppa, F.; Paoli, A.; Iovane, A.; et al. The effects of physical training without equipment on pain perception and balance in the elderly: A randomized controlled trial. Work 2017, 57, 23-30. [CrossRef]

17. Pahor, M. Falls in Older Adults: Prevention, Mortality, and Costs. JAMA 2019, 321, 2080-2081. [CrossRef]

18. Lacroix, A.; Hortobagyi, T.; Beurskens, R.; Granacher, U. Effects of Supervised vs. Unsupervised Training Programs on Balance and Muscle Strength in Older Adults: A Systematic Review and Meta-Analysis. Sports Med. 2017, 47, 2341-2361. [CrossRef] 
19. Gine-Garriga, M.; Roque-Figuls, M.; Coll-Planas, L.; Sitja-Rabert, M.; Salva, A. Physical exercise interventions for improving performance-based measures of physical function in community-dwelling, frail older adults: A systematic review and meta-analysis. Arch. Phys. Med. Rehabil. 2014, 95, 753-769.e3. [CrossRef]

20. Bellafiore, M.; Battaglia, G.; Bianco, A.; Paoli, A.; Farina, F.; Palma, A. Improved postural control after dynamic balance training in older overweight women. Aging Clin. Exp. Res. 2011, 23, 378-385. [CrossRef]

21. Wong-Yu, I.S.; Mak, M.K. Multi-dimensional balance training programme improves balance and gait performance in people with Parkinson's disease: A pragmatic randomized controlled trial with 12-month follow-up. Parkinsonism Relat. Disord. 2015, 21, 615-621. [CrossRef]

22. Karlsson, M.K.; Vonschewelov, T.; Karlsson, C.; Coster, M.; Rosengen, B.E. Prevention of falls in the elderly: A review. Scand. J. Public Health 2013, 41, 442-454. [CrossRef]

23. de la Hoz, J.G.; Padilla-Fortes, A.; Padilla-Ruiz, M. Análisis de incidentes por resbalones ocurridos en piscinas de España, 2000-2015. SPORT TK-Rev. Euroam. Cienc. Deporte 2019, 8, 21-30. [CrossRef]

24. Selby, S.; Hayes, C.; O'Sullivan, N.; O'Neil, A.; Harmon, D. Facilitators and barriers to green exercise in chronic pain. Ir. J. Med. Sci. 2019, 188, 973-978. [CrossRef]

25. Bowler, D.E.; Buyung-Ali, L.M.; Knight, T.M.; Pullin, A.S. A systematic review of evidence for the added benefits to health of exposure to natural environments. BMC Public Health 2010, 10, 456. [CrossRef]

26. Calogiuri, G.; Chroni, S. The impact of the natural environment on the promotion of active living: An integrative systematic review. BMC Public Health 2014, 14, 873. [CrossRef]

27. Granacher, U.; Gollhofer, A.; Hortobagyi, T.; Kressig, R.W.; Muehlbauer, T. The importance of trunk muscle strength for balance, functional performance, and fall prevention in seniors: A systematic review. Sports Med. 2013, 43, 627-641. [CrossRef]

28. Gillespie, L.D.; Gillespie, W.J.; Robertson, M.C.; Lamb, S.E.; Cumming, R.G.; Rowe, B.H. Interventions for preventing falls in elderly people. Cochrane Database Syst. Rev. 2003. [CrossRef]

29. Poulton, G.; Funderburke Matney, B.; Williams, T.; Hulkower, S.; Stigleman, S. Exercise to Reduce Falls in Older Adults. Am. Fam. Physician 2020, 101, 42-43.

30. Morris, J.N.; Hardman, A.E. Walking to health. Sports Med. 1997, 23, 306-332. [CrossRef]

31. Okubo, Y.; Osuka, Y.; Jung, S.; Rafael, F.; Tsujimoto, T.; Aiba, T.; Kim, T.; Tanaka, K. Walking can be more effective than balance training in fall prevention among community-dwelling older adults. Geriatr. Gerontol. Int. 2016, 16, 118-125. [CrossRef]

32. Lee, I.M.; Buchner, D.M. The importance of walking to public health. Med. Sci. Sports Exerc. 2008, 40, S512-S518. [CrossRef] [PubMed]

33. Jarvis, J.C. The Relationship between Activity Pattern and Muscle Adaptation in Skeletal Muscle. Artif. Organs 2015, 39, 863-867. [CrossRef] [PubMed]

34. Mawase, F.; Bar-Haim, S.; Shmuelof, L. Formation of Long-Term Locomotor Memories Is Associated with Functional Connectivity Changes in the Cerebellar-Thalamic-Cortical Network. J. Neurosci. 2017, 37, 349-361. [CrossRef] [PubMed]

35. Thivel, D.; Tremblay, A.; Genin, P.M.; Panahi, S.; Riviere, D.; Duclos, M. Physical Activity, Inactivity, and Sedentary Behaviors: Definitions and Implications in Occupational Health. Front. Public Health 2018, 6, 288. [CrossRef]

36. Pajala, S.; Era, P.; Koskenvuo, M.; Kaprio, J.; Tormakangas, T.; Rantanen, T. Force platform balance measures as predictors of indoor and outdoor falls in community-dwelling women aged 63-76 years. J. Gerontol. A Biol. Sci. Med. Sci. 2008, 63, 171-178. [CrossRef]

37. Scoppa, F.; Gallamini, M.; Belloni, G.; Messina, G. Clinical Stabilometry Standardization: Feet Position in the Static Stabilometric Assessment of Postural Stability. Acta Med. Mediterr. 2017, 33, 707-713. [CrossRef]

38. Cohen, J. Statistical Power Analysis for the Behavioral Sciences; Lawrence Erlbaum Associates Publishers: Mahwah, NJ, USA, 1988.

39. Borysiuk, Z.; Pakosz, P.; Konieczny, M.; Krecisz, K. Intensity-Dependent Effects of a Six-Week Balance Exercise Program in Elderly Women. Int. J. Environ. Res. Public Health 2018, 15, 2564. [CrossRef]

40. Battaglia, G.; Bellafiore, M.; Bianco, A.; Paoli, A.; Palma, A. Effects of a dynamic balance training protocol on podalic support in older women. Pilot Study. Aging Clin. Exp. Res. 2010, 22, 406-411. [CrossRef]

41. Madureira, M.M.; Takayama, L.; Gallinaro, A.L.; Caparbo, V.F.; Costa, R.A.; Pereira, R.M. Balance training program is highly effective in improving functional status and reducing the risk of falls in elderly women with osteoporosis: A randomized controlled trial. Osteoporos. Int. 2007, 18, 419-425. [CrossRef] 
42. Ebrahim, S.; Thompson, P.W.; Baskaran, V.; Evans, K. Randomized placebo-controlled trial of brisk walking in the prevention of postmenopausal osteoporosis. Age Ageing 1997, 26, 253-260. [CrossRef]

43. Okubo, Y.; Osuka, Y.; Jung, S.; Figueroa, R.; Tsujimoto, T.; Aiba, T.; Kim, T.; Tanaka, K. Effects of walking on physical and psychological fall-related factors in community-dwelling older adults: Walking versus balance program. J. Phys. Fit. Sports Med. 2014, 3, 515-524. [CrossRef]

44. Sousa, N.; Mendes, R.; Silva, A.; Oliveira, J. Combined exercise is more effective than aerobic exercise in the improvement of fall risk factors: A randomized controlled trial in community-dwelling older men. Clin. Rehabil. 2017, 31, 478-486. [CrossRef] [PubMed]

45. Hrysomallis, C. Relationship between balance ability, training and sports injury risk. Sports Med. 2007, 37, 547-556. [CrossRef]

46. Row Lazzarini, B.S.; Kataras, T.J. Treadmill walking is not equivalent to overground walking for the study of walking smoothness and rhythmicity in older adults. Gait Posture 2016, 46, 42-46. [CrossRef]

47. Calogiuri, G.; Evensen, K.; Weydahl, A.; Andersson, K.; Patil, G.; Ihlebaek, C.; Raanaas, R.K. Green exercise as a workplace intervention to reduce job stress. Results from a pilot study. Work 2015, 53, 99-111. [CrossRef]

48. Gregg, E.W.; Pereira, M.A.; Caspersen, C.J. Physical activity, falls, and fractures among older adults: A review of the epidemiologic evidence. J. Am. Geriatr. Soc. 2000, 48, 883-893. [CrossRef]

49. El-Khoury, F.; Cassou, B.; Charles, M.A.; Dargent-Molina, P. The effect of fall prevention exercise programmes on fall induced injuries in community dwelling older adults: Systematic review and meta-analysis of randomised controlled trials. BMJ 2013, 347, f6234. [CrossRef]

50. American College of Sports Medicine; Chodzko-Zajko, W.J.; Proctor, D.N.; Fiatarone Singh, M.A.; Minson, C.T.; Nigg, C.R.; Salem, G.J.; Skinner, J.S. American College of Sports Medicine position stand. Exercise and physical activity for older adults. Med. Sci. Sports Exerc. 2009, 41, 1510-1530. [CrossRef]

51. Dipietro, L.; Campbell, W.W.; Buchner, D.M.; Erickson, K.I.; Powell, K.E.; Bloodgood, B.; Hughes, T.; Day, K.R.; Piercy, K.L.; Vaux-Bjerke, A.; et al. Physical Activity, Injurious Falls, and Physical Function in Aging: An Umbrella Review. Med. Sci. Sports Exerc. 2019, 51, 1303-1313. [CrossRef]

52. World Health Organization. Global Recommendations on Physical Activity for Health; World Health Organization: Geneva, Switzerland, 2010.

53. Slaght, J.; Senechal, M.; Bouchard, D.R. Impact of Walking Cadence Prescription to Reach the Global Physical Activity Recommendations in Older Adults. J. Aging Phys. Act. 2017, 25, 604-611. [CrossRef]

54. Trott, M.; Smith, L. What are the associations between extroversion, enjoyment, and wellness in group vs non-group physical activity? A pilot study. Atena J. Sports Sci. 2019, 1, 1-11. 